ORIGINAL ARTICLE

\title{
Assessment of Calprotectin as a Serodiagnostic Marker for Neonatal Sepsis
}

\author{
Tarek Hamed Attia ${ }^{1}$, Hatem Mohammed Hussien ${ }^{1}$, Ahmed Morad Asaad ${ }^{2}$, Ziad Ahmed Esmat ${ }^{1}$ \\ ${ }^{1}$ Pediatrics Department, Faculty of Medicine, Zagazig University, Zagazig, Egypt \\ ${ }^{2}$ Microbiology and Immunology Department, Faculty of Medicine, Zagazig University, Zagazig, Egypt
}

Corresponding Author:

Ziad Ahmed Esmat

Pediatrics

Department,Faculty of

Medicine, Zagazig

University, Zagazig, Egypt

E-mail:

ziadghost@hotmail.com

\section{ABSTRACT}

Background: Despite recent advances in neonatal care, sepsis remains a worldwide leading cause of morbidity, mortality and prolonged hospital stay in NICUs, so that the accurate and early diagnosis of neonatal sepsis is a relevant problem. Calprotectin is an antimicrobial, calcium and zinc binding heterocomplex protein that could be used as a nonspecific marker for activation of granulocytes and mononuclear phagocytes. Therefore, calprotectin has been proposed for the diagnosis of inflammatory conditions.

Objective: This study aimed to evaluate the diagnostic value of serum Calprotectin in newborns with suspected sepsis.

Methods: This case control study comprised 40 neonates, 20 neonates with suspected clinical sepsis and other 20 healthy neonates with no clinical signs of sepsis as a control group. Serum level of calprotectin was measured for all neonates recruited in this study, by a commercial ELISA assay

Results: Among the cases group, a total of 15 neonates (75\%) had positive blood culture. Serum calprotectin levels were significantly higher in septic group than non- septic and control groups as mean Serum Calprotectin was $2.5 \pm 0.95 \mu \mathrm{g} / \mathrm{ml}, 1.58 \pm 0.25 \mu \mathrm{g} / \mathrm{ml}$ and $1.01 \pm 0.29 \mu \mathrm{g} / \mathrm{ml}$, respectively.

Significant positive correlations were found between calprotectin levels and WBCs and IM ratio, while negative correlations were found between its level and lymphocytes and platelets. In our study, Calprotectin sensitivity and specificity values were $92 \%$ and $93.3 \%$, respectively.

Conclusion: Serum calprotectin levels were significantly higher in neonates with sepsis. Its levels correlated well with other laboratory markers of sepsis and neonatal mortality. It is a sensitive diagnostic marker for neonatal sepsis.

Keywords: Neonatal sepsis, diagnosis, serum calprotectin

\section{INTRODUCTION}

De espite the recent advances in neonatal care, sepsis remains a worldwide leading cause of morbidity, mortality and prolonged hospital stay in neonatal intensive care units. As according to the world health organization (WHO), more than $40 \%$ of under-five years deaths globally occur in the neonatal period, resulting in 3.1 million newborn deaths each year ${ }^{(1)}$. About 1 million of these deaths are attributed to infectious causes including neonatal sepsis, meningitis, and pneumonia ${ }^{(2)}$.

Neonatal sepsis is defined as a clinical syndrome of bacteremia with systemic signs and symptoms of infection in the first 4 weeks of life ${ }^{(3)}$. The incidence of sepsis in neonatal period is much greater than any other period of life. This incidence varies from one place to another as some studies in the developed countries reported that the incidence of neonatal sepsis ranged from 1 to 5 cases per 1000 live births, while this incidence in the developing countries ranged from 49 - 170 per 1000 live births ${ }^{(4)}$. A recent study from Egypt reported that neonatal septicemia incidence ranged from $20-25 \%{ }^{(5)}$.

Neonatal sepsis is reported to be responsible for $30-50 \%$ of the total neonatal 
deaths in developing countries. It is estimated that up to $20 \%$ of the neonates develop sepsis and approximately $1 \%$ die of sepsis related causes ${ }^{(6)}$.

Because the signs and symptoms of neonatal sepsis are nonspecific and the clinical course may be fulminating, so early diagnosis and prompt treatment remains a challenge facing neonatologists. ${ }^{(7)}$

The golden standard for diagnosis of septicemia is the isolation of bacterial agents from the blood culture. Unfortunately, results are usually not available before 48-72 hours and could be negative in many situations even in cases of a pure clinical picture of septicemia. Therefore, a myriad of studies on various diagnostic markers like hematological indices, acute phase reactants, C-reactive protein, procalcitonin, cytokines, and cell surface markers and many others ${ }^{(8)}$.

Neonatal septicemia is associated with hyper inflammatory host responses that subtend activation of immune system, so a broad spectrum of inflammatory markers has been proposed for the diagnosis of neonatal sepsis, one of these markers is Calprotectin ${ }^{(9)}$.

Calprotectin is an antimicrobial, calcium and zinc binding heterocomplex protein contained in the cytosol fraction of innate immunity cells and released immediately after host-pathogen interaction. Also, Calprotectin protects cells against invasive microorganisms and regulates adhesion of leukocytes to the endothelium and extracellular matrix during the inflammatory process. Calprotectin is detectable in body fluids by means of a simple ELISA technique, so Calprotectin has been proposed for the diagnosis of many inflammatory conditions. However, its use in the diagnosis of neonatal sepsis remains unexplored ${ }^{(10)}$. The aim of this study was to assessment the diagnostic power of serum calprotectin in neonatal sepsis.

\section{MATERIALS AND METHODS}

A written informed consent was obtained from all guardians of all participants and the study was approved by the research ethical committee of Faculty of Medicine,
Zagazig University. The work has been carried out in accordance with The Code of Ethics of The World Medical Association (Declaration of Helsinki) for studies involving humans.

Study Design and Population: This case control study was conducted at neonatal intensive care unit, children hospital, Zagazig University during the period from June 2018 to February 2019. A total sample of 20 cases with suspected septicemia (Cases group) and another 20 healthy matched neonates with no clinical signs of sepsis (Control group) was included in the present study.

\section{Clinical criteria suggesting sepsis:}

At the time of inclusion, all neonates in cases group had one or more of the following criteria:

2.2.1- Fever (temperature $>38^{\circ} \mathrm{C}$ ) or hypothermia (temperature $<35^{\circ} \mathrm{C}$ ).

2.2.2- Respiratory signs (apnea, respiratory distress and cyanosis).

2.2.3- Neurologic signs (hypotonia, weak reflexes, impairment of consciousness, convulsions, coma and irritability).

2.3.4- Digestive signs (refusal to suck, abdominal distension, vomiting, and diarrhea).

\section{Exclusion criteria:}

2.3.1- Neonates received antibiotics more than 2 days prior to inclusion.

2.3.2- Neonates with any congenital anomalies.

2.3.3- Parents refused to sign consent to be involved in the study.

\section{All newborns enrolled in this study were subjected to:}

- History taking including: Prenatal, natal, postnatal and present history.

- Clinical examination:

- Weight, age and sex.

- Gestational age using last menstrual period date \& new Ballard score.

- Complete clinical examination to detect clinical signs of sepsis.

- Laboratory investigations:

- Complete blood count.

- Sepsis screen (CRP, Blood culture) at time of inclusion.

- Serum calprotectin. 
- SGOT, SGPT, serum creatinine and random blood sugar.

\section{Laboratory Procedures:}

- Complete blood counts were done by cell counter, leukocytes were differentiated by microscopy then the I/M ratio was calculated as the sum of immature granulocytes divided by the mature ones ${ }^{(11)}$. The CRP was measured using CRP Quantikine ELISA kits (R\&D, Minneapolis, MN, USA)

- As for blood culture, about $1 \mathrm{~mL}$ of venous blood was collected from each neonate under complete aseptic conditions, and inoculated directly into blood culture medium vials (BacT/ALERT $®$ PF Plus bottels, Biomerieux, $\mathrm{NC}$, USA), incubated at $37^{\circ} \mathrm{C}$ and examined each 24 hours and any growth was identified according to the standard microbiological protocol $^{(12)}$.

- Serum calprotectin:

Blood samples were collected from all neonates in plain tubes, allowed to clot at room temperature and then centrifuged at $10.000 \mathrm{rpm}$ for $10 \mathrm{~min}$. Serum calprotectin was measured by standard doubleantibody sandwich enzyme-linked immunosorbent assay (ELISA) technique ${ }^{(10)}$, using commercial kit (Human Calpro ELISA Kit, SunRed, Shanghai, China).

\section{STATISTICAL ANALYSIS}

Data were collected throughout history, basic clinical examination, laboratory investigations; and outcome measures were coded, entered and analyzed using Microsoft Excel software. Clinical characteristics and laboratory variables were compared using Chi square test, agreement by Kappa, t test, ANOVA, Kruskal Wallis, Pearson's correlation, Spearman's, and logistic regression analysis. Statistical significance was defined as a $p$-value less than 0.05 and $<0.001$ for highly significant result. All analysis was performed with the Statistical Package for the Social Sciences (SPSS), version 20.0 (SPSS Inc., Chicago, IL, USA).

\section{RESULTS}

Among the cases group, a total of 15 (75\%) neonates had positive blood culture and considered as the septic group, while the 5 $(25 \%)$ neonates with no growth of their cultures were treated as non-septic group.

Both of the demographic and laboratory data of control, non- septic and septic groups were presented in table (1). No significant differences were present as regards mean age, gestational age, sex, birth weight or mode of delivery.

Significant differences were observable as regarding mean values of WBCs levels $(p=0.001)$, platelet counts $(p=0.037)$, CRP levels $(p=0.009)$ and IM ratio $\quad(p=0.001$. Calprotectin levels were significantly higher in septic group than non - septic and control group $(p=0.001)$.

Significant differences between cases and control groups were present as regarding clinical presentation at the time of inclusion ( $p=0.01)$. Among cases group, most common clinical symptoms were respiratory distress $(65 \%)$, poor activity ( $55 \%)$, feeding intolerance ( $30 \%$ ), hypothermia and poor perfusion $(25 \%)$ and hyperthermia ( $15 \%)$. Distribution of clinical symptoms among studied groups were presented in table (2).

Serum calprotectin concentration was significantly higher in the septic group than in the non-septic and control groups (Figure 1). Distribution of serum calprotectin among studied groups was presented in table (3). The sensitivity, specificity, positive and negative predictive values were $93.3 \%, 92.0 \%, 87.5 \%$, $95.8 \%$, respectively. Serum calprotectin was positively correlated with WBCs and IM ratio, while was negatively correlated with lymphocytes and platelets (Figures 2,3 and S1).

In the current study, Klebsiella and GBS were the most common organisms isolated from blood of sepsis group (8 isolates; 53.3\%: $26.6 \%$ for each), followed by Staph. aureus (3 isolates 20\%), Pseudomonas species (2 isolates $13.3 \%$ ) and both E. coli and CoNS (One isolate; $6.6 \%$ for each pathogen).

Six cases $(30 \%)$ died within one week of admission, all of them were blood culture positive (2 of them were positive for Pseudomonas species, 2 for Klebsiella, 1 for 
GBS and 1 for Staph. aureus). Cases with positive blood cultures and poor outcomes had the highest levels of serum calprotectin (Table $5)$.

Table (1): Comparison between control, septic and control groups as regards demographic and laboratory data

\begin{tabular}{|c|c|c|c|c|c|}
\hline & & $\begin{array}{l}\text { Control } \\
(\mathrm{N}=20)\end{array}$ & $\begin{array}{l}\text { Non- septic } \\
\quad(\mathrm{N}=5)\end{array}$ & $\begin{array}{l}\text { Septic } \\
(\mathrm{N}=15)\end{array}$ & $\mathrm{P}$ \\
\hline Age / day & $\begin{array}{c}\text { Range } \\
\text { Mean } \pm \text { SD }\end{array}$ & $\begin{array}{c}(3-27) \\
8.95 \pm 5.8\end{array}$ & $\begin{array}{c}(1-12) \\
5.71 \pm 1.54\end{array}$ & $\begin{array}{c}(1-26) \\
7.86 \pm 4.62\end{array}$ & 0.143 \\
\hline $\begin{array}{l}\text { Birth weight } \\
\text { / KG }\end{array}$ & $\begin{array}{c}\text { Range } \\
\text { Mean } \pm \text { SD }\end{array}$ & $\begin{array}{l}(1.6-3.6) \\
2.9 \pm 0.42\end{array}$ & $\begin{array}{c}(2.1-2.8) \\
2.52 \pm 0.32\end{array}$ & $\begin{array}{c}(1.5-3.9) \\
2.53 \pm 0.65\end{array}$ & 0.109 \\
\hline $\begin{array}{l}\text { Gestational age } \\
\text { / weeks }\end{array}$ & $\begin{array}{c}\text { Range } \\
\text { Mean } \pm \text { SD }\end{array}$ & $\begin{array}{c}(35-39) \\
37.5 \pm 1.43\end{array}$ & $\begin{array}{c}(35-39) \\
36.6 \pm 1.51\end{array}$ & $\begin{array}{c}(31-39) \\
35.93 \pm 2.52\end{array}$ & 0.069 \\
\hline Sex & $\begin{array}{c}\text { Males } \\
\text { Females }\end{array}$ & $\begin{array}{c}9(45.0 \%) \\
11(55.0 \%)\end{array}$ & $\begin{array}{l}4(80.0 \%) \\
1(20.0 \%)\end{array}$ & $\begin{array}{l}8(53.3 \%) \\
7(46.7 \%)\end{array}$ & 0.37 \\
\hline Delivery mode & $\begin{array}{c}\text { Vaginal } \\
\text { Caesarian }\end{array}$ & $\begin{array}{l}7(35.0 \%) \\
13(65.0 \%)\end{array}$ & $\begin{array}{l}2(40.0 \%) \\
3(60.0 \%)\end{array}$ & $\begin{array}{c}4(26.7 \%) \\
11(73.4 \%)\end{array}$ & 0.71 \\
\hline HB & $\begin{array}{c}\text { Range } \\
\text { Mean } \pm \text { SD }\end{array}$ & $\begin{array}{c}(9.8-17.4) \\
13.82 \pm 2.09\end{array}$ & $\begin{array}{l}(11.4-17.5) \\
13.88 \pm 2.31\end{array}$ & $\begin{array}{c}(8.8-19.7) \\
15.32 \pm 3.26\end{array}$ & 0.233 \\
\hline Platelets & $\begin{array}{c}\text { Range } \\
\text { Mean } \pm \text { SD }\end{array}$ & $\begin{array}{c}(153-474) \\
246.45 \pm 74.94\end{array}$ & $\begin{array}{c}(138-412) \\
266.8 \pm 103.3\end{array}$ & $\begin{array}{c}(35-365) \\
179.13 \pm 75.7\end{array}$ & $0.037 *$ \\
\hline WBCs & $\begin{array}{c}\text { Range } \\
\text { Mean } \pm \text { SD }\end{array}$ & $\begin{array}{c}(6-18.7) \\
9.96 \pm 2.76\end{array}$ & $\begin{array}{l}(10.1-17.9) \\
12.52 \pm 3.22\end{array}$ & $\begin{array}{c}(5-22.6) \\
15.58 \pm 5.5\end{array}$ & $0.001 * *$ \\
\hline IM ratio & $\begin{array}{c}\text { Range } \\
\text { Mean } \pm \text { SD }\end{array}$ & $\begin{array}{l}(0.06-0.12) \\
0.096 \pm 0.01\end{array}$ & $\begin{array}{l}(0.09-0.16) \\
0.12 \pm 0.02\end{array}$ & $\begin{array}{c}(0.14-0.22) \\
0.18 \pm 0.02\end{array}$ & $0.001 * *$ \\
\hline CRP & $\begin{array}{c}\text { Range } \\
\text { Mean } \pm \text { SD }\end{array}$ & ---------- & $\begin{array}{c}(6-12) \\
8.0 \pm 2.7\end{array}$ & $\begin{array}{c}(18-48) \\
30.46 \pm 11.35\end{array}$ & $0.009 *$ \\
\hline $\begin{array}{c}\text { Serum } \\
\text { calprotectin }\end{array}$ & $\begin{array}{c}\text { Range } \\
\text { Mean } \pm \text { SD }\end{array}$ & $\begin{array}{c}(0.5-1.4) \\
1.01 \pm 0.29\end{array}$ & $\begin{array}{l}(1.2-1.9) \\
1.58 \pm 0.25\end{array}$ & $\begin{array}{l}(1.7-4.8) \\
2.5 \pm 0.95\end{array}$ & $0.001 * *$ \\
\hline
\end{tabular}

$*=$ Significant

$* *=$ highly significant 
Table (2): Distribution of clinical symptoms among studied groups

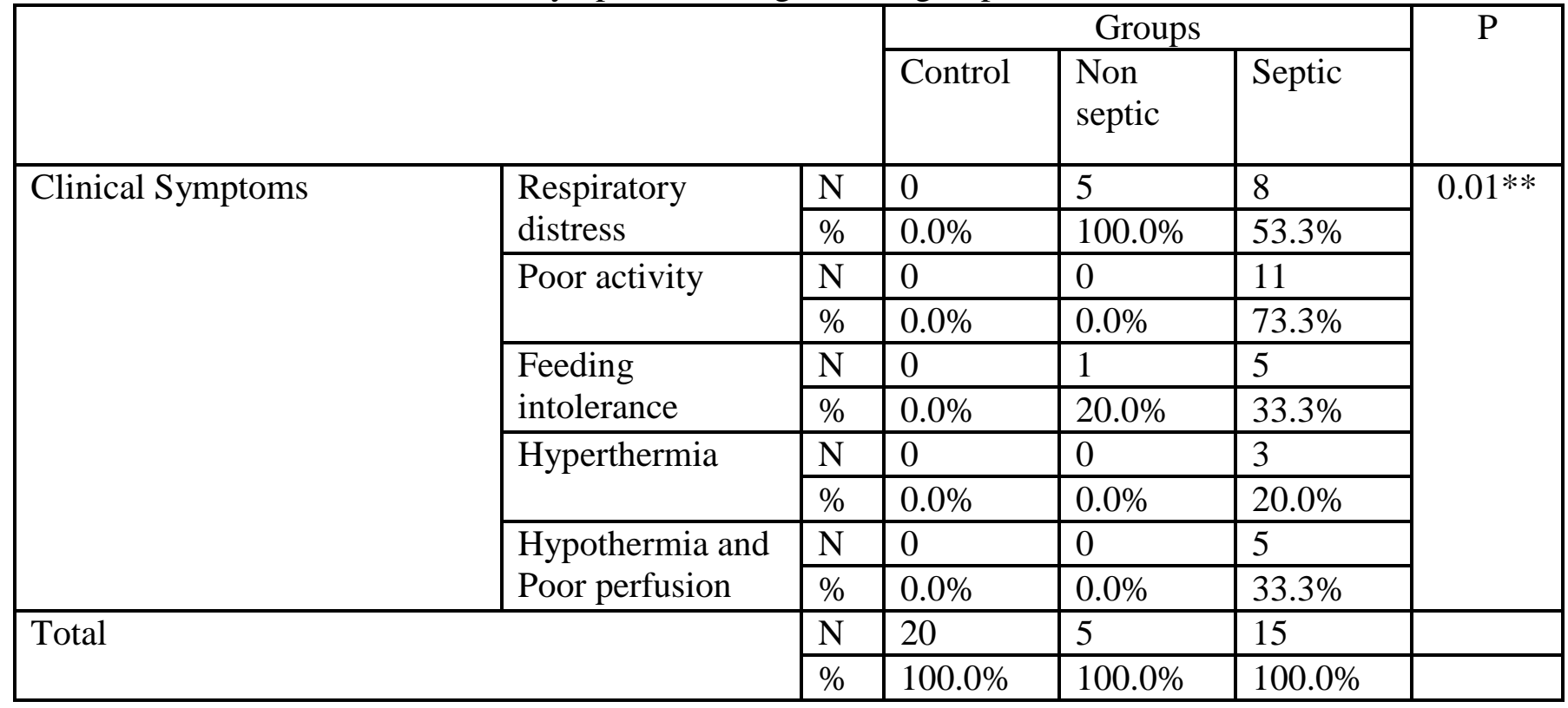

$* *=$ Highly significant

Table (3): Distribution of serum calprotectin among studied groups

\begin{tabular}{|l|l|c|c|c|c|}
\hline \multicolumn{2}{|l|}{} & $\begin{array}{c}\text { Control } \\
(\mathbf{N = 2 0})\end{array}$ & $\begin{array}{c}\text { Non septic } \\
(\mathbf{N}=5)\end{array}$ & $\begin{array}{c}\text { Septic } \\
(\mathbf{N = 1 5})\end{array}$ & P \\
\hline $\begin{array}{l}\text { Serum } \\
\text { Calprotectin }\end{array}$ & Mean \pm SD & $1.01 \pm 0.29$ & $1.58 \pm 0.25$ & $2.5 \pm 0.95$ & $\mathbf{0 . 0 0 1} * *$ \\
& Median & 1.1 & 1.6 & 2.1 \\
& Range & $0.5-1.4$ & $1.2-1.9$ & $1.7-4.8$ & \\
& & & & & \\
\hline
\end{tabular}

$* *=$ Highly significant 
Table (4): Comparison between calprotectin and CRP levels in cases group as regards blood culture and outcome

\begin{tabular}{|c|c|c|c|c|}
\hline \multirow{2}{*}{} & \multicolumn{2}{|c|}{ Blood culture } & \multicolumn{2}{c|}{ Outcome } \\
\cline { 2 - 5 } & $\begin{array}{c}\text { Positive } \\
(\mathrm{N}=15)\end{array}$ & $\begin{array}{c}\text { Negative } \\
(\mathrm{N}=5)\end{array}$ & $\begin{array}{c}\text { Survived } \\
(\mathrm{N}=14)\end{array}$ & $\begin{array}{c}\text { Died } \\
(\mathrm{N}=6)\end{array}$ \\
\hline $\begin{array}{c}\text { Serum calprotectin } \\
\text { Mean } \pm \text { SD } \\
\text { Median } \\
\text { Range }\end{array}$ & $\begin{array}{c}2.5 \pm 1.04 \\
2.1\end{array}$ & $\begin{array}{c}1.5 \pm 0.25 \\
1.6\end{array}$ & $\begin{array}{c}1.8 \pm 0.32 \\
1.85 \\
(1.2-2.6)\end{array}$ & $\begin{array}{c}3.26 \pm 1.32 \\
3.2\end{array}$ \\
& $(1.7-4.8)$ & $(1.2-1.9)$ & $(1.7-4.8)$ \\
\hline P value & \multicolumn{2}{|c|}{0.118} & & $0.04 *$ \\
\hline CRP & $30.46 \pm 11.35$ & $8.0 \pm 2.7$ & $19.7 \pm 16.7$ & 15 \\
Mean \pm SD & 24 & 6 & $(6-48)$ & $28 \pm 9.7$ \\
Median & $(18-48)$ & $(6-12)$ & $24-48)$ \\
\hline Range & \multicolumn{2}{|c|}{$0.035^{*}$} & & $0.007 * *$ \\
\hline
\end{tabular}

$*=$ Significant

$* *=$ highly significant

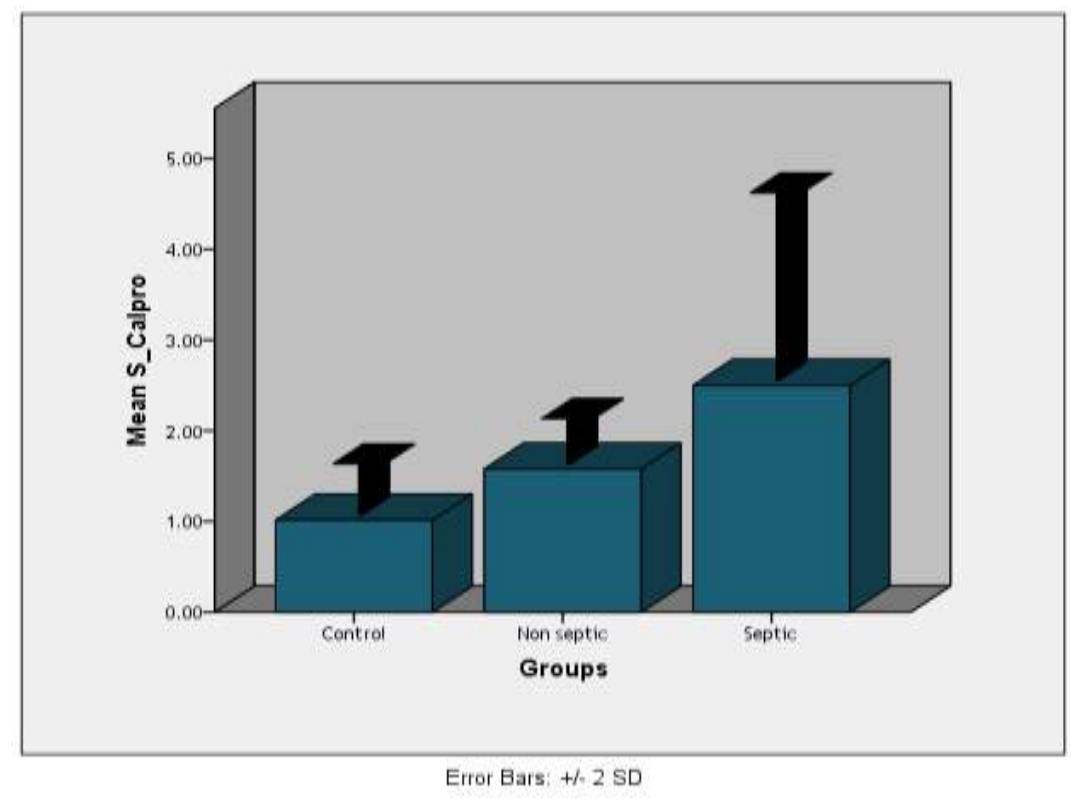

Figure 1. Serum calprotectin is significant higher in septic group than other two groups 


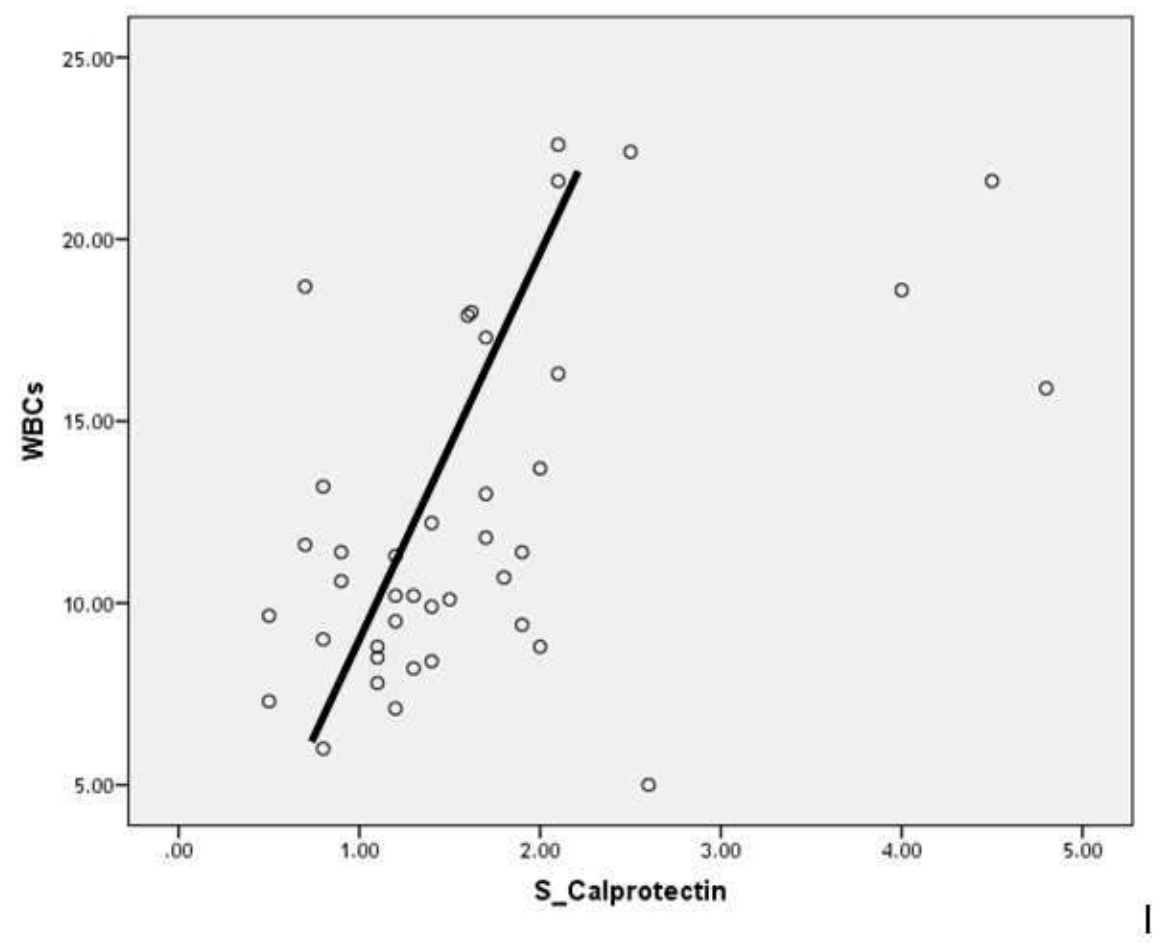

Figure 2. Correlation between levels of serum calprotectin and WBCs

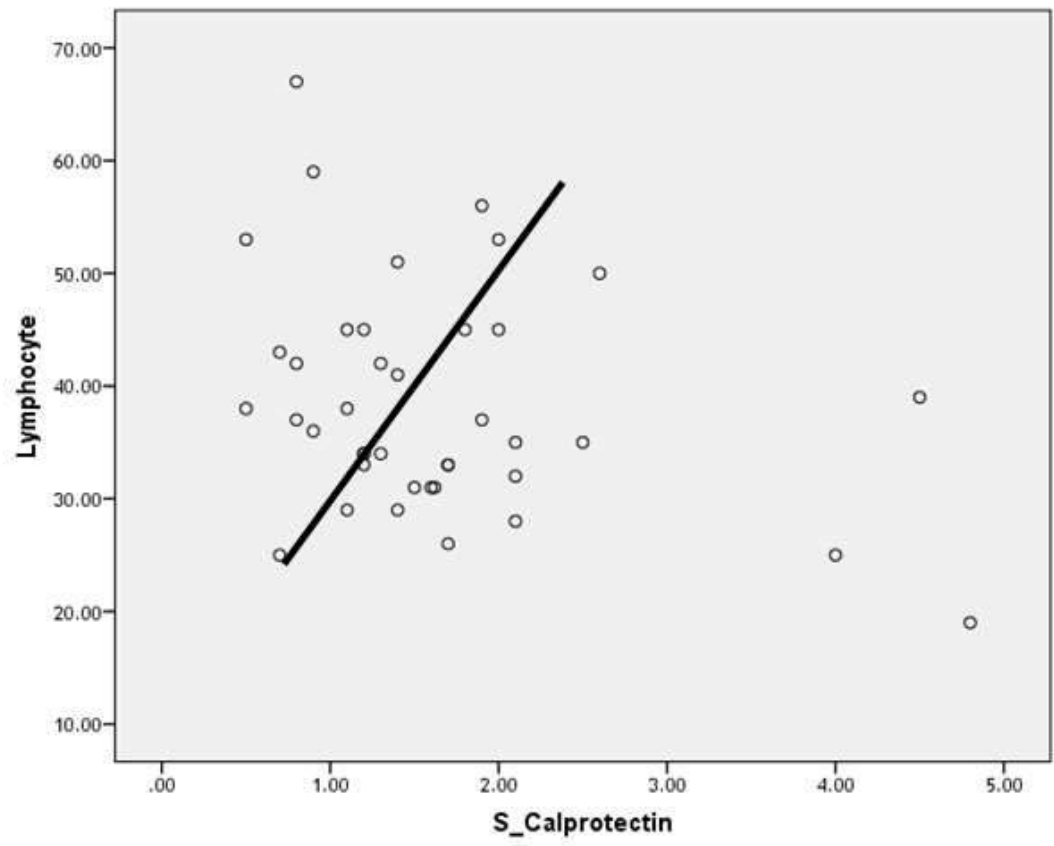

Figure 3. Correlation between levels of serum calprotectin and Lymphocytes 


\section{DISCUSSION}

Neonatal sepsis is a common life threatening inflammatory syndrome characterized by systemic signs of infection, and accompanied by bacteremia in the first 28 days of life. As sepsis in the neonatal period is the most common cause of morbidity and mortality and the clinical signs and symptoms of neonatal sepsis are vague non-specific, so early accurate diagnosis is the main corner stone for neonatologists ${ }^{(3)}$.

An ideal marker for sepsis should guarantee an early diagnosis; therefore many markers have been studied for such mission ${ }^{(13)}$. Calprotectin, a complex of two calcium-binding proteins that belong to the $\mathrm{S} 100$ protein family, is one of these promising markers, has been proposed for the diagnosis of many inflammatory conditions ${ }^{(14)}$.

The aim of our study was to evaluate if serum calprotectin can be used as a marker for early diagnosis of neonatal sepsis. The data obtained show that serum Calprotectin levels were significantly higher in septic neonates than both non septic and control groups with Mean of $(2.5 \pm 0.95,1.58 \pm 0.25$ and $1.01 \pm 0.29$ $\mu \mathrm{g} / \mathrm{ml}$ respectively, $p$-value $=0.001$ ).

In a previous similar study conducted in Egypt, Abdel-Maaboud et al. ${ }^{(13)}$ reported that calprotectin levels were significantly higher in the positive cultures $(5800 \pm 610 \mathrm{ng} / \mathrm{mL})$ compared to the negative cultures $(3200 \pm 1300$ $\mathrm{ng} / \mathrm{mL})(P=0.002)$. In a similar study from Indonesia, Riskawa et al. ${ }^{(17)}$ reported the mean concentrations of plasma calprotectin to be 144,490 and $10,310 \mathrm{ng} \backslash \mathrm{mL}$ in 10 preterm septic neonates and non-septic neonates, respectively.

In the current study, the specificity and sensitivity values of calprotectin were $92 \%$ and $93,3 \%$, respectively. While In another research, Decembrino et al. ${ }^{(10)}$ reported the specificity and sensitivity of calprotectin to be $69.7 \%$ and $62.5 \%$, respectively. As for Abdel-Maaboud et al. ${ }^{(13)}$, the specificity and sensitivity values were $94.0 \%$ and $91,3 \%$, respectively.

In this study, the cases group included 20 neonates with suspected clinical sepsis, among them 15 neonates (75\%) had positive blood culture and 6 cases (30\%) died, all were positive blood culture. It was observed that levels of serum calprotectin were higher in died neonates than survived infants $(p=0.047)$. So this study revealed that there was significant association between level of serum calprotectin and outcome. Many previous studies support this finding as Abdel-Maaboud et al. ${ }^{(13)}$, Shams et al. ${ }^{(18)}$ and Terrin et al. ${ }^{(14)}$. All of these researchers reported that died cases had the highest level of Serum Calprotectin.

In the current study, Serum Calprotectin was positively correlated with WBCs and I:M ratio, while was negatively correlated with lymphocytes and platelets.

The CRP, an acute-phase protein involved in coagulation, is a biomarker widely used in diagnosis of sepsis ${ }^{(15)}$. Results of this study showed that CRP was significant higher in septic group than non-septic group. Other researchers such as Abdel-Maaboud et al. ${ }^{(13)}$ and Terrin et al. ${ }^{(14)}$ reported the same results as for CRP level among neonates with sepsis.

The WBC counts and ratios may be helpful for evaluation of sepsis, but they are still non-specific and have low positive predictive value as some neonates who are not infected show abnormal WBC counts related to the stress of delivery and the I:T ratio is the most sensitive indicator of sepsis ${ }^{(16)}$. In our study, WBC counts were significantly higher than non-septic and control groups. This result goes in agreement Abdel-Maaboud et al. ${ }^{(13)}$, while other studies Decembrino et al. ${ }^{(10)}$ and Shams et al. ${ }^{(18)}$ reported no significance difference between septic and non-septic groups as regards WBCs counts. Differently, the $\mathrm{I} / \mathrm{M}$ ratio was significant higher in the septic compared to other groups. And for platelets, septic group was significantly lower than other groups.

As for clinical symptoms, among the cases group: Respiratory distress (65\%), poor activity (55\%), feeding intolerance (30\%), hyperthermia (15\%) and hypothermia and poor perfusion were the most common presenting symptoms. 
To conclude, the main aim of this current study was to evaluate if serum Calprotectin can be used as a marker for early diagnosis of sepsis. The data obtained showed that the plasma concentration of calprotectin was higher in neonates with sepsis. The plasma levels of calprotectin was not influenced by gestational age, sex, age at enrollment or mode of delivery. This promising data approved that serum Calprotectin could be a practical marker in the diagnostic approach to neonates with suspected septicemia.

\section{CONCLUSION}

In the fact, diagnosis of sepsis in newborns cannot be based on a single biological marker, and actually blood culture remains the golden standard for diagnosis. Our study aimed to introduce Calprotectin as a promising, early, sensitive and specific marker for sepsis diagnosis thanks to the importance of calprotectin in defense mechanisms and physiological functions of the immune system.

\section{Declaration of interest}

The authors report no conflicts of interest. The authors alone are responsible for the content and writing of the paper.

\section{Funding information}

None declared

Figure S1: is shown in the online supplement

\section{REFERENCES}

1. Oestergaard MZ, Inoue M, Yoshida S, Mahanani WR, Gore FM, Cousens S, Lawn JE and Mathers CD. Neonatal mortality levels for 193 countries in 2009 with trends since 1990: a systematic analysis of progress, projections, and priorities. PLoS medicine 2011; 8 (8):e1001080.

2. Black RE, Cousens S, Johnson HL, Lawn JE, Rudan I, Bassani DG, Jha P, Campbell H, Walker CF, Cibulskis R, Eisele T, Liu L and Mathers C. Global, regional, and national causes of child mortality in 2008: a systematic analysis. Lancet 2010; 375 (9730):1969-87.

3. Kale A, jaybhaye D and Bonde V. Neonatal Sepsis: An Update. Iran J Neonatol 2014; 4 (4):39-51.

4. Thaver D and Zaidi AK. Burden of neonatal infections in developing countries: a review of evidence from community-based studies. Pediatr Infect Dis J 2009; 28 (1 Suppl): 3-9.
5. El-Din S, Rabie EM, El-Sokkary MMA, Bassiouny MR and Hassan R. Epidemiology of neonatal sepsis and implicated pathogens: a study from Egypt. Bio Res internat 2015; 2015: p. 1-11.

6. Gandhi S, Ranjan K, Ranjan N, Sapre N and Masani M. Incidence of neonatal sepsis in tertiary care hospital: an overview. Int $J$ Med Sci Public Health 2013; 2 (3): 548-553.

7. Gerdes JS. Diagnosis and management of bacterial infections in the neonate. Pediatr Clin 2004; 51 (4):939-959.

8. Hornik CP, Benjamin DK, Becker KC, Benjamin Jr DK, Li J, Clark RH, Cohen-Wolkowiez M and Smith PB. Use of the complete blood cell count in early-onset neonatal sepsis. The Pediatr infect dis $J$ 2012; 31 (8):799.

9. $\mathrm{Ng}$ PC. Diagnostic markers of infection in neonates. Arch Dis Child Fetal Neonatal Ed, 2004. 89(3): p. F229-35.

10. Decembrino L, De Amici M, Pozzi M, De Silvestri A and Stronati M. Serum Calprotectin: A Potential Biomarker for Neonatal Sepsis. $J \quad$ of Immunol Res 2015; 2015: P. 1-4.

11. Geaghan SM. Hematologic values and appearances in the healthy fetus, neonate, and child. Clin lab med 1999; 19 (1): 1-38.

12. Spanjaard L, Kuijper E and Dankert J. Clinical comparison of two commercial blood culture systems. Eur J Clin Microbiol Inf Dis 2000; 19 (11): 881-885.

13. Abdel-Maaboud M, El-Mazary A-AM and Osman AM. Serum calprotectin as a diagnostic marker of late onset sepsis in full-term neonates. Egy J Pediatr Allergy Immunol 2012; 10 (1): P.19-24.

14. Terrin G, Passariello A, Manguso F, Salvia G, Rapacciuolo L, Messina F, Raimondi F and Canani RB. Serum calprotectin: An antimicrobial peptide as a new marker for the diagnosis of sepsis in very low birth weight newborns. Clin Develop Immunol 2011; 2011 (291085) p.1-6.

15. Chiesa C, Panero A, Osborn JF, Simonetti AF and Pacifico L. Diagnosis of neonatal sepsis: A clinical and laboratory challenge. Clin Chem 2004; 50 (2): 279-287.

16. Shah BA and Padbury JF. Neonatal sepsis: An old problem with new insights. Virulence 2014; 5 (1): 170-178. 
17. Riskawa HK, Hilmanto D and Chairulfatah A. Serum calprotectin in preterm infants with and without sepsis neonatorum. J Ind Med Associat 2013; 62 (04).

18. Shams SF, Boskabadi H, Keramati MR, Ayatollahi $H$, Shakeri S, Sheikhi $M$ and
Sadeghian MH. Evaluation of Immature Neutrophil Ratio and Calprotectin Level for the Diagnosis of Neonatal Sepsis. Iran J Neonatol IJN $2017 ; \quad 8 \quad$ (3): $19-24$.

To Cite This Article: Attia TH, Hussien HM , Asaad AM, Esmat ZA. Assessment of Calprotectin as a Serodiagnostic Marker for Neonatal Sepsis. ZUMJ 2019;25(5);577-586,DOI: 10.21608/zumj.2019.10031.10980 